\title{
Multi-scale modelling of AISI H11 martensitic tool steel surface anisotropic mechanical behaviour
}

\author{
Ahmed Zouaghi $^{1,2}$, Vincent Velay ${ }^{1}$, Adriana Soveja ${ }^{2}$ and Farhad Rézaï-Aria ${ }^{1}$ \\ ${ }^{1}$ Université de Toulouse; INSA, UPS, Mines Albi, ISAE; ICA (Institut Clément Ader), Campus \\ Jarlard, 81013 Albi Cedex 09, France \\ ${ }^{2}$ Université de Toulouse; INSA, UPS, Mines Albi, ISAE; ICA (Institut Clément Ader), 10 Avenue \\ Edouard Belin, 31055 Toulouse Cedex 4, France
}

\begin{abstract}
In this work, a numerical investigation is carried out on the anisotropic and heterogeneous behaviour of the AISI H11 martensitic tool steel surface using finite element method and a multi-scale approach. An elasto-viscoplastic model that considers nonlinear isotropic and kinematic hardenings is implemented in the finite elements code ABAQUS using small strain assumption. The parameters of the constitutive equations are identified using macroscopic quasi-static and cyclic material responses by the mean of a localization rule. Virtual realistic microstructures, consisting of laths and grains, are generated using particular Voronoï tessellations. These microstructures consider the specific crystallographic orientations $\alpha^{\prime} / \gamma$. Finite element investigation is then performed. The local heterogeneous and anisotropic behaviour of the surface as well as the subsurface is shown under quasi-static and cyclic mechanical loadings. The laths morphology and crystallographic orientation have an important impact on the local mechanical fields.
\end{abstract}

\section{Introduction}

During forming and machining processes, surface and subsurface of metallic materials (both tools and parts) are experiencing cyclic thermo-mechanical and quasi-static loadings in particular shearing. Under such solicitations, the microstructure on subsurface presents a pronounced anisotropic microstructural aspect resulting from shear strain gradient and the grain crystallographic orientations, morphology, and grains interactions, that develops a textured grains and gradient beneath the surface.

Many investigations on thermo-mechanical behaviour and life assessments of metallic materials use macroscopic models [1, 2]. They consider in general the microstructure as an isotropic and homogeneous media by neglecting any microstructural heterogeneity. To better get insight into the local mechanical behaviour of the surface, a multi-scale approach is very much of concern for life prediction of metallic alloys by taking into account the microstructure anisotropic aspects.

\section{Numerical methodology}

In this contribution, a multi-scale modelling is used to describe the local behaviour of an AISI H11 martensitic hot work tool steel surface. The constitutive equations of Méric and Cailletaud [3] are 
written at the martensitic lath scale using the finite element code ABAQUS. The parameters of these equations are identified under macroscopic quasi-static and cyclic loadings by the mean of a localisation rule [4] (Fig. 1).
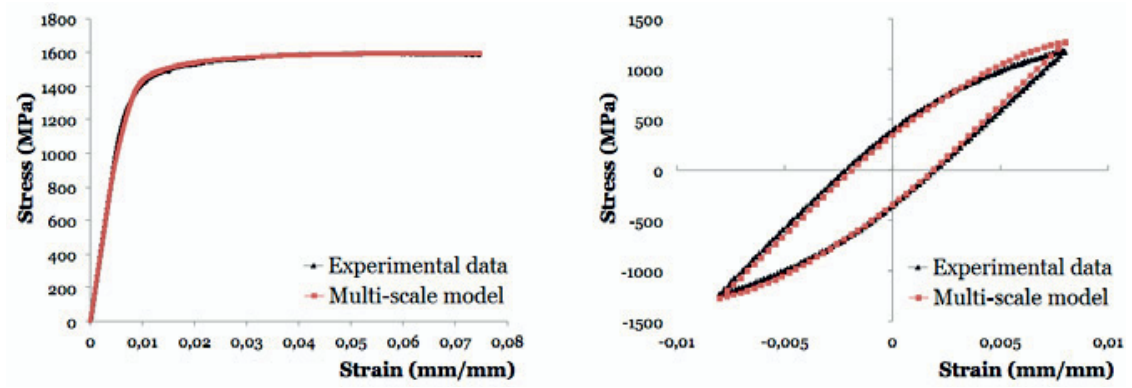

Figure 1. Material parameters identification (a) quasi-static uniaxial response (b) cyclic response

By using particular Voronoï tessellations, virtual realistic microstructures, consisting of laths and grains, are generated considering the specific crystallographic orientations $\alpha$ ' $\gamma$ (i.e. Kurdjumov-Sachs relation). The pronounced anisotropic microstructures are characterized by relative translated and rotated laths on the surface.

A numerical investigation using finite elements method is then conducted on the different microstructure sets to highlight the local material anisotropic quasi-static and cyclic mechanical behaviours.

\section{Principle results}

The finite element analysis have revealed that the morphology and crystallographic orientations have an impact on the local cyclic and quasi-static mechanical behaviour on the surface and the subsurface of the AISI H11 martensitic steel (Fig. 2). This methodology emphasizes the interaction effect where the mechanical fields on the subsurface depend on the orientations and morphology of the surface laths.
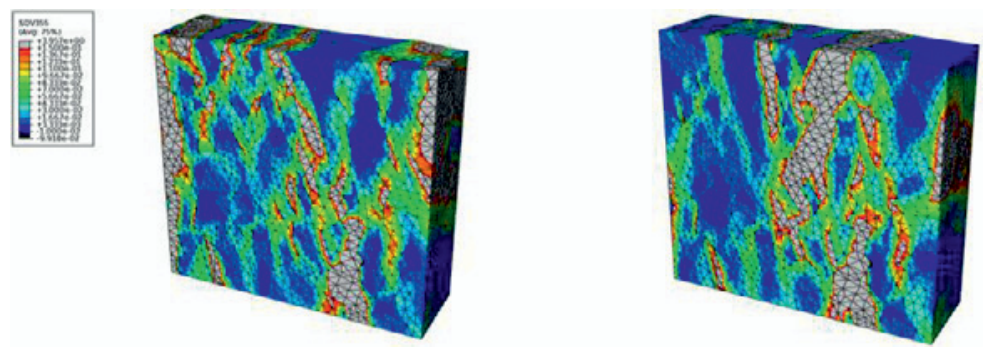

Figure 2. Von Mises equivalent plastic strain contour maps of AISI H11 subjected to uniaxial quasi-static macroscopic strain of $8 \%$ for two orientations sets

\section{References}

1. V. Velay, G. Bernhart, L. Penazzi, Int. J. of Plast. 22, 28 (2006)

2. Z. Zhang, G. Bernhart, D. Delagnes, Int. J. of Fat. 30, 11 (2008)

3. L. Méric, G. Cailletaud, J. of Engng. Mat. Technol. 113, 12 (1991)

4. P. Pilvin, G. Cailletaud, Rev. Eur. des Eléments finis 3, 37 (1994) 